Review Article

\title{
BODY DONATION AS GIFT TO MEDICAL SCIENCE FOR BETTER TOM ORROW - LITERATURE REVIEW
}

\author{
Meera Jacob ${ }^{1}$, R K Avadhani $^{2}$, Rani Nallathamby ${ }^{3}$, Meril Ann Soman ${ }^{4} \&$ Bindhu $\mathbf{S}^{5}$ \\ ${ }^{1}$ Assistant Professor, ${ }^{2}$ Professor \& HOD, ${ }^{3,4}$ Post Graduates, ${ }^{5}$ Associate Professor, Department of Anatomy, \\ Yenepoya Medical College, M angalore, Karnataka, India. \\ Correspondence : \\ Bindhu S \\ Associate Professor, Department of Anatomy, Yenepoya Medical College, Mangalore - 575 018, Karnataka, India. \\ Mobile : +919945666156 E-mail : nairbindhu@yahoo.com
}

\begin{abstract}
:
Anatomy is one of the basic and very important subject studied by medical students at the beginning of their medical career. Best method for learning anatomy is by dissection of human cadavers and this forms an indispensable part of training health care professionals. Since the numbers of medical institutions are increasing, there is an increased demand of cadavers for anatomic dissection. Body donation is an act of donating one's body after death for medical research and education. In this article an attempt has been made to collect literature related to body donation, its importance and the ethical issues related to body donation.
\end{abstract}

Keywords: Anatomy, dissection, body donation, medical education

\section{Introduction:}

Anatomy is the study of structure of human body and forms the basic subject studied by undergraduate and postgraduate students. Dissection of human cadavers forms an integral part of anatomy learning and research. Only source for the cadavers in the medical institutions will be unclaimed bodies and few donated bodies. As the number of medical colleges are increasing in the present scenario, most of the medical schools experience difficulties in obtaining adequate number of cadavers ${ }^{1}$. At present, unclaimed bodies are the main source of cadavers that is coming from the authorised government institutions. So the body donation programmes should be encouraged by the medical schools and regular campaigns must be held to create awareness among the public regarding Body donation.

\section{Significance of Body Donation :}

Access this article online Quick Response Code

\begin{tabular}{|c|}
\hline 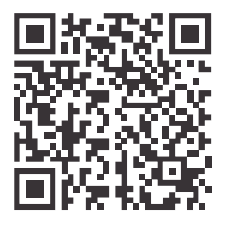 \\
\hline
\end{tabular}

Anatomical donation or body bequest is defined as act of giving one's body after death for medical education and research and thus a person can give back to society a chance to learn something that can influence generations to come. Delmas suggested that the donation is a clear will made by persons free and informed ${ }^{2}$.Body donation is considered as an ultimate gift which should be appreciated by the educators. Availability of textbooks and internet information cannot replace the cadaveric dissection in learning anatomy .So hands on experience provided by the cadaveric dissection is superior to other artificial sustitutes ${ }^{3}$. Apart from learning anatomy it is also used for developing new surgical techniques ${ }^{3}$. Body donation is the preferred source of availability of cadavers' worldwide ${ }^{4}$.

\section{History:}

In ancient India human body was dissected by shushruta by about 500 B.C. It was his belief that for one to be a skilful surgeon, one must first be an Anatomist. Even though the issue of using humans for dissection was in opposition to religious law, it was an essential tool for true understanding of human Anatomy ${ }^{6}$.The concept of acquiring knowledge by dissection of human body initially started in the fifteenth century and it was initially done by Andreas Vesalius (1514-1564). Slowly and steadily the importance was realised. Once autopsy was accepted to establish the cause of death, importance of dissection was more enlightened. By establishment of Anatomy act 1832, 
unclaimed bodies were used for anatomic dissection ${ }^{7}$.By $18^{\text {th }}$ and $19^{\text {th }}$ century, the anatomical dissection became very popular in Unite States medical education. When the demand for cadaveric supply increased, the thefts by grave robbers became more common and sold the bodies to medical schools for dissection ${ }^{7}$. Murder act established in 1752 , permitted the use of corpses of executed criminals for dissection. Donation of body to science was unheard till Jeremy Bentham, philosopher donated his body to science in $1832^{5}$.

\section{Body Donation and Anatomy Act :}

Body donation is regulated by various acts according to each country and is considered as the expression of solidarity .In U.K, the Anatomy act was passed in 1832 which permitted the donation of the body of the deceased by his kin. This permitted doctors, teachers of Anatomy and bonafide medical students to dissect donated bodies. This act was replaced by Anatomy act 1924, which was in turn replaced by Human Tissue Act $2004^{5}$. In India, Anatomy act was enacted in 1949 and is adopted by all states. It calls for the supply of unclaimed bodies to medical and teaching institutes for the purpose of anatomical dissection and for research purposes. It can be donated by relatives of deceased according to dead person's wishes ${ }^{1}$. Anatomy act is a state act published in State Government Gazette .According to this almost anyone can donate for medical research and education. It provides for the collection of a dead body for teaching purpose, only if death occurs in a state hospital or in public place within prescribed zone of medical institution , provided that police have declared a lapse of 48 hours that there are no claimants for the body and it could be used for medical purpose ${ }^{8}$.Patnaik suggested that a draft act should be made for all the states to use as model for amendment of anatomy acts in order to avoid the discrepancies existing between any two or more acts $^{9}$.

\section{Factors Affecting Body Donation :}

There are few researches that are conducted to know the factors that influence the willingness of body donation. Boulware et al showed that the important factors that can influence body donation will be race, ethinicity, demographic factors, awareness about body donation, age, sex, education, occupation, income, religious aspects and so on. He conducted a study among the households of Maryland and observed that the older age is negatively associated with willingness to donate cadaveric organs ${ }^{10}$. He also showed that demographic and attitudinal factors were also involved in the decision to donate one's own body. Armstrong in his study noted that younger age group were more willing to donate when compared to older one in Australia ${ }^{11}$.Similar finding was also recorded by Alashek et al, noted that lack of adequate knowledge, unease about body manipulation and religious implications were the barriers for cadaveric donation ${ }^{12}$.Golchet et al reported that many factors like age,culture,personality characteristics, views on death and mortality and humanitarian concerns influence people's opinion towards body donation ${ }^{13}$.Bolt et al revealed that there are three principal factors motivating Dutch people for body donation like desire to be useful after death, negative attitude towards funeral and expression of gratitude ${ }^{14}$. Rokad and Gaikawad noted that the reasons for Indian donors to donate their bodies was due to the fact that the body should be utilised for mankind's benefit than being burnt to death ${ }^{5}$. Negative factors that can affect body donation were also studied. Most important factor for less number of body donation in Indians is due to lack of awareness. Few of the general population are aware of body donation ${ }^{14}$. The attitude of anatomists towards body donation is not well known. Organ donation is more preferred when compared to body donation not only by general population but also by the medical personnals ${ }^{5}$.

\section{Role of Social Networks:}

Society should play a major role in motivating the people to donate their bodies for training of medical and other health care professionals. According to Cantorovitch, main reasons for "No body donation" are due to lack of awareness, religious uncertainities, distrust of medicine and hostility of new ideas. In the present scenario, mass media can play a major role in motivating the society ${ }^{15}$. Conesa et al studied the influence of television, press and 
magazines, hoarding and posters, campaign about donation, information given by health professionals regarding body donation. It was observed that media with greater impact was television, second was press and radio, the third being magazines and talks with health professionals ${ }^{16}$.

\section{Body Donation Programme :}

Body donation is a generous and unselfish act for those who wish to be useful to living after death. There is no substitute for cadaveric dissection in learning anatomy and new surgical techniques. Body donation units should be established in all medical schools and awareness programmes should be designed. That factors that can cause repulsion for body donation should be taken care. Awareness programmes should be started with the help of mass media Alashek et al suggested that public educational campaigns should be conducted with religious

\section{References:}

1. Ajita R. Singh YI. Body Donation and Its Relevance in Anatomy Learning. J Anat Soc India 2007; 56(1): 2-7

2. Delmas V. Donation of bodies to science. Bull Acad Natl Med: 2001; 185 (5): 849-856. Lemmp H K. Perceptions of dissection by students in one medical school: beyond learning about anatomy. A qualitative study. M ed Educ: 2005; 39: 318-325

3. Agthong S,and Wiwanitkit V.Cadaver donation:a retrospective review at the king chulalongkorn memorial Hospital,Bangkok.The southeast Asian journal of tropical medicine and public health 2002; Suppl:166-7

4. Sehirli US, Saka E, Sarikaya O. Attitude of Turkish anatomists toward cadaver donation. Clin Ana. 2004; 17(8): 677-681

5. Rokade $S A, B a h e t e e$ BH.Body donation ,A Review.Medical Journal of Western India.2013;41(1):36-40

6. Marios Loukas,Alexis Lanteri,Julie Ferraciola,R.Shane Tubbs.Anatomy in Ancient India:A focus on the Susruta Samhita.J.Anat(2010)217, pp646-650.

7. Rath G,Garg K.Inception of cadaver dissection and its relevance in present day scenario of medical education.J Indian Med Assoc.2006 Jun;104(6):331-3.

8. Subramanium B.V.Law in relation to medical men In:Modi's medical Jurisprudence and Toxicology .22 edition;Butterworths .New Delhi.pp.724-727.

9. Patnaik,V.V.G.(2002):Editorial .JAnatSocIndia;50(2):143-44. leadership ${ }^{12}$. Donors should be assured that their bodies will be treated with dignity and respect. Practise of honouring the cadavers at the commencement of medical course by students and teachers as followed in Korea ${ }^{17}$ should be followed in all medical schools.

\section{Conclusion :}

Dissection of human cadavers is compulsory for medical education. So one cadaver dissection can teach many doctors who can treat thousands of patients and can be a relief to their loved ones. So the decision of an individual to donate his/her body is gift for advancement of medical sciences. Government should encourage and educate the public to create awareness about organ and body donation. Body donation is the act of giving one's body after death without any conditions for education and research in medicine.

10. Boulware LE, Ratner LE, Cooper LA, LaVeist TA, Powe NR. Whole body donation for medical science: a population -based study. Clin Anat 2004;17(7);570-7.

11. Armstrong GT. Age: an indicator of willingness to donate. J Transplant Coord 1996;6(4):171-3.

12. Alashek W, Ehtuish E, Elhabashi A, Emberish W, Mishra A. Reasons for unwillingness of Libyans to donate organs after death. Lybian J Med 2009:4(3):110-3

13. Golchet, G.,Carr,J.and Harris,M .G:Why do'nt we have enough cornea donors?.A literature review and Survey.Optometry;71(5):318-28.

14. Bolt S, VenbruxE, Eisinga R, KuksJB, VeeningJG, Gerrits PO. M otivation for body donation to science: more than an altruistic act. Ann Anat 2010; 192(2):70-4

15. Cantarovich F. Public opinion and organ donation suggestions for overcoming barriers. AnnTransplant: 2005; 10(1): 22-25

16. Conesa C, Rios Zambudio A, Ramirez P, Canteras M, Rodriguez M M, Parrilla P. Influence of different sources of information on attitude toward organ donation: a factor analysis. Transplant Proc:2004; 36(5): 1245-1248.

17. ParkJT, Jang Y, Park M S, Pae C, ParkJ, Hu KS, ParkJ S, Seung-Ho Han, KiSeok Koh, Hee-Jin Kim. The trend of body donation for education based on Korean social and religious culture. Anat Sci Educ 2011;4:33- 